\title{
Psychometric Intelligence and Academic Achievement, A Comparative Analysis of Elementary Schools
}

\author{
Sunita Malhotra \\ Strategic Human Resources Management Course, Warsaw University of \\ Technology Business School, Poland \\ sunita.malhota3119@gmail.com
}

Article History:

Received: Nov $10^{\text {th, }} 2019$

Revised: Jan $13^{\text {th, }} 2020$

Accepted: March 30th, 2020

\begin{abstract}
Intelligence and achievement are two distinct, yet complementary build-ups. The deliberate researches in centennial an effort was made to achieve to reveal the differentiation in scholastic and existential consequences. School achievement may be considered a result of the total growth pattern of the child. Growth in interest and attitudes towards learning is as important as growth in knowledge. Learning methods of solving problems is fully as valuable as the facts gained or improvements made in school or community in the process. The present research focuses on primary school children's academic achievement and Intelligence level. The sample for the present study consisted of 150 students from a distinct variety of schools such as NGO based schools, a Government school and Private primary schools of the different regions of India. The Raven's Coloured Progressive Matrices was used for measuring the IQ level of the students and for measuring the Academic Achievement, Achievement Test Battery of Singh (ATB-SR), 2008 which consists of tests Hindi, English, Mathematics, Science and Social Science. The results revealed that there was a notable dissimilarity into the achievement scores of Hindi, English, Mathematics, Science and Social Science of the NGO's based school, government and private school students. Important implications for educational practices may derive from these findings since they can provide valuable information to design instructional actions and programs that can improve student achievement and satisfaction.
\end{abstract}

Keyword: Academic achievement, progressive, matrices, Battery test (ATB-SR), Intelligence Quotient, government, NGO's

\section{INTRODUCTION}

India is a vast country with diverse socio-cultural contexts and widely varying geographical and climatic conditions. The Constitution was modified in 1976 to alter pedagogy from state of affairs to concurrent one which implies that the responsibility for the expansion of pedagogy goes fifty-fifty in by Central and State 
Governments. The National Policy on Education (1986) which was revised in 1992 anticipated the expansion of education is follow as four phases of schooling viz. primary, upper primary, secondary and higher secondary.

This phase foresees the primary's five years, upper primary three years, secondary two and senior secondary two. The pre-primary stage, which is being considered as a critical stage for putting the groundwork for primary education, is currently not a part of the formal education structure.

The current policy framework envisages ensuring access to ECCE opportunities mainly through the Integrated Child Development Services (ICDS) in the public channel and through other service providers, particularly for reaching the marginalized and vulnerable groups.

The leading scheme for universalization of primary education is the Sarva Shiksha Abhiyan. The withholding objective of the Sarva Shiksha Abhiyaan is: (i) every single one of the children in schools; (ii) reconcile all gender and social category disparity at primary and upper primary phases of pedagogy (iii) universal withholding; (iv) primary education of adequate standard.

The remarkable progress in the direction of widespread admittance enrolment: In the year 2013-14 the number of primary schools with a primary section only has augmented from 638,738 to 858,916 in comparison to the year 2000-01. And the upper primary goes from 206,269 to 589,796. Figure 1 and Figure 2 showing the above data in graphical form.

Nationally, all but 98 percent of primary schools come in the vicinity of $1 \mathrm{~km}$ of the countryside habitat. The enlistment in elementary education in the year 2000-01 has augmented in the year 2013-14 from 113.8 million to 132.4 million. School achievement tests are principally designed to measure the intellectual knowledge and skills acquired through education (Helms-Lorenz \& Van de Vijver, 1995). This type of intelligence is known as crystallized intelligence (Cattell\& Butcher, 1968 cited in Helms-Lorenz \& Van de Vijver, 1995). Academic achievement is one in all the necessary social indicators that relate to a range of positive outcomes that people value.

Researchers have found that the increasingly competitive environments of schools present many challenges before students and how these students typically respond to challenges has a lot to do with how much they achieve (Theobold, 2005).

All these factors collectively contributed to the academic achievement of students. These subjects are interrelated too. Language Development -Interest in the language is still strong in this period vocabulary increase and sentences improve in grammatical correctness, in tenses, and fluency. Language is basic to thought and communication. Linguistic development is part of mental development.

The cultural background may make a difference of as much as eight months in the linguistic development of children of the upper and the lower social classes. The school is equally responsible for making a noticeable degree of progress in 
language development. Arithmetic Development-When the child enters the fifth grade his knowledge of the fundamental computations, the language of arithmetic, as well as capacity to apply thinking in situations involving number should be inventoried.

Among the components related to achievement in problem-solving in fifth-grade arithmetic is Arithmetic factors such as skill in fundamental operations Ability to think abstractly with numbers and to estimate the answers to problems General reasoning ability; ability to note differences, likenesses, and spatial relations, memory and ability to draw inferences General language ability Skill in the reading of graphs, charts, tables.

Science and Social Studies -Students of these grades generally have an avid interest in facts. They are keenly interested in ancient plants and animals, astronomy, magnetism, the earth, and it's surface. Reports concerned with instructions sciences emphasize the basic importance of studying the local community, beginning with an apprehension of human relations in the class group and attaining off towards broader relations.

Gradually through social studies in grades four to eight, pupils should achieve a growing understanding of their role in the world today. Research in these subjects, as in spelling and arithmetic, indicates the need for a map of values, uncluttered by insignificant detail. Parallel with this elimination of deadwood, several trends are noticeable, to devote time to science, it provides more opportunity for experimentation and discovery, to use informal school activities as opportunities for teaching the ways of democracy, to use community resources and improve the local community, to apply the problem approach in these fields, and to integrate each study with other subject areas.

The students having poor academic records are probably denied access to higher education as well as to enter the reputed schools which further enhance the educational performance gap. Individuals having higher academic performance have higher self-esteem, lower levels of depression and anxiety which are again considered to be crucial inputs in commitment to academic success.

Therefore, the academic performance gap is growing with the ages, which is coined as 'Cumulative Advantage Process (CAP)' by Merton (1973). The report aims to give an extensive review of intellectual and mental capacity and their association with each other. Figure 5 showing the interconnectedness model which depicts that family, school, and community collectively do affect the all-round development of a child. Education has undeviating out-turn on children's pedagogy achievement, their accretion of reading and writing proficiency, mathematical ability and technical acquaintance.

The learning of specific knowledge and skills is a direct effect of classroom teaching (Good \&Brophy, 1986b). Nevertheless, social abstraction and notions do sway by curriculum instructions and in return, they forecast the upshot as 
intelligence or school curriculum. These roundabout out-turn of schools are difficult to find because they are intervened by pupils' motivation to understand or forebear from learning, their inception of oneself as students, and the classification they make to understand success and failure. During their early and formative years, children spend half their waking hours in school.

It is for that reason, it anticipated that schools and teachers will help to mold student's evolution and fortune. Countries infuse much amount in the schools as these will evolve the existence of young ones upon which the future of the society and country relies upon. So, it is but obvious to expect from the schools that they qualified the students to use their potential fully in the learning and achievement process run by the pedagogy curriculum. Schooling and school are not the wholesale responsible for the process of evolution of a child. It includes socioeconomic factors, condition of the home environment, the attitude of parents towards their children, community background. The details and awareness of the specific culture which imbibes the roots of the student which in turn changes their existence towards life.

\section{LITERATURE REVIEW}

Gottfredson (1998) stated, "Intelligence computed by IQ test is by itself the nearly all effectual prognostication known of one's conduction at school and on the work". Lindquist (1957) defined achievement as the degree of ability to perform on predetermined facts and concepts both quantitatively and qualitatively. Intelligence has been considered as the most important cognitive factor that explains variations in achievement scores.

The causal effect of IQ on scholastic conduct was a probe in a crosshead board study conducted by Wakins, Lei, and Canivez (2007). It has been assessed by comparing the test-retest interval of 2.8 years method of on 289 students and documented that psychometric IQ had an intermittent influence on future achievement, but achievement does not have an influence or impact on the forthcoming IQ.

Sylva (1994) reviews the extensive literature related to the effect of schools and schooling on the development of the child. Habibullah \& Ashrafbullah (2013) studied the various factors which influence the theoretical attainment of the elementary school children and found that younger age, female gender, better socio-economic condition, the practice of taking breakfast, better state of the school, consistent presence in the class all these were positively correlated with better academic performance. Gouda, Das, Goli \& Pou (2014) identify the disparity among government and private primary schools in terms of basic infrastructure, tuition costs and students' performance. Indian Human Development Survey (IHDS, 2005) surveyed and reported that the result presents a picture of government and private school. It is clear-cut from the survey that 
private primary schools are forerunners in terms of all the indicators. Also, the basic infrastructure and teaching do affect the performance of the students. Singh (2014) investigating and trying to check the position of academic achievement at government and private high school in the Manipur state, the research analyzes the data of High School Leaving Certificate Examination in Manipur, pass and fail\% in the overall and sex-wise category during 2009-2011.

The findings reveal that the overall scholastic conduct of the government schools' private schools is different in every year 2009, 2010 and 2011. It was found that notable distinction in the school wise scholastic achievement of the students. Imam, Singh \& Tiwari (2016) explores the outturn of gender and school type on the scholastic attainment of the students of Lucknow district.

The tools used here are Personal Information Questionnaire and Academic achievement judged based on the school report cards. The finding of the study brings into being that the achievement level of students of equally private and government schools were low. Besides its girls and boys of both private schools were better than their counterparts of a government school.

Anandharaja, Balakrishna \& Lawrence (2016) examine the scholastic attainment of the students of $X$ grade in the social sciences program of the three districts of south viz. Thanjavur, Kumbakonam and Patttukkottai Educational District. The construct used for the study was the Academic Achievement Test in Social Sciences (AATSS) developed by the investigator itself.

The result revealed that there exists a notable disparity among the scholastic attainment of private and government schools. Rural school girls and boys show a significant difference between government and private school but not in the urban one. Cuesta, Glewwe \& Krause (2015) explores the both economic and education literature published from 1999 to 2012 to analyze the outcome of school infrastructure on the learning and enrolment.

The study brings into being that the toilet facility improved student learning in addition to those laboratories, drinking water facilities increase the enrolment also. Agarwal \& Chugh (2003) investigates the achievement level of the children living in the slum. A total of 4 slums were selected for the study purpose. The achievement level of the Ist and IVth standard besides its oral achievement test both in literacy and numeracy, paper-pencil achievement test in language and mathematics, school profile, student profile, the household profile of the children living in the slum was assessed.

The mean achievement scores of slum children studying in government schools were low. In a comparative framework too, the performance of slum children was low. So, it is evident that not only school but the social and economic factor of the family was too equally important for the achievement of the students. 


\section{Conceptual Framework Of The Study}

The conceptualization of intelligence has received attention for over a century. Sternberg (2003) catalog the definitions of intelligence formulated by diversified investigators' capacity of quality feedback from the perspective of reality and actuality (Thorndike), the capacity to bring on speculative thinking (Terman) and so on. So, it can be stated that it is not purely book learning, a narrow down scholastic skill, or test-taking smarts.

Rather, it reproduces a wider and greater capacity for understanding our surroundings - "holding on," "rendering sense" of things, or "guessing out" what to do. As attainment is a comprehensive and multidimensional concept (Jackson, 1976), the meaning or comprehension of the construct may highlight several dimensions. According to Koretz (1997), the notion of learning achievement is explicitly applied in social science to suggest to the mastery of expertise and skills. It knows how to also be defined as presented upon a specific test and skill. Intelligence has been considered as the most important cognitive factor that explains variations in achievement scores. As a result, the association between conventional intelligence and educational achievement is now well established (Jensen, 1998). There is a broad agreement that intelligence needs a positive impact on educational outcomes, the magnitude of the correlation has had little consistency across studies, being reported as somewhere from moderate to sturdy (Fischer et al., 1996; Herrnstein \& Murray, 1994). Apart from these both factors, the one more thing which does affects these two is the type of school.

So keeping in mind all the relationships between all these variables, the present research has proposed this conceptual framework figure no. 6 which shows that the three different types of primary schools i.e. government, private and NGO based schools do effect the Intelligence Quotient and Academic Achievement of the students.

\section{Objectives of The Study}

The study aims to identify the difference between the student's Intelligence Quotient (IQ) and Academic Achievement of the Government, Private, and NGO's based schools by assessing the Intelligence Quotient and Academic Achievement of the primary school students and identifying the effect of school type on the academic achievement of the primary school students as well as identifying the effect of school type on the intelligence of the primary school students. The study also tries to find out the relationship between Intelligence Quotient and Academic Achievement.

\section{METHOD}

The present study used the Raven's Colored Progressive Matrix developed by Raven (1990) to measure the intelligence of the students. The CPM is 
internationally recognized as a culture-fair test of nonverbal intelligence, outline to work with children among the ages of $5 \frac{1}{2}$ to $11 \frac{1}{2}$. The handout record of the test was used and it was administered in cluster set (Raven, Court \& Raven, 1990). The Colored Progressive Matrices (CPM), has three Sets A, Ab, B, are arranged to assess the chief cognitive processes of children under 11 years of age. The test-retest reliability studies of the CPM show that in a normative Indian Study, found a product-moment correlation of .86. And the validity of the test found to be .75 . The Achievement Test Battery ATB-SR developed by Singh (2008) was used to assess the Scholastic Achievement of the primary school students. A battery test consisted of a series of tests of Hindi, English, Mathematics, Science and Social Science. The test is based on the curriculum of the 4th standard and 5th standard. There are 25 questions related to English and Hindi, 50 questions of mathematics and Science and 75 questions related to Social Science. The reliability of the test found to be $.92, .91, .91, .91$, and .92 respectively for the subjects Hindi, English, Mathematics, Science and Social Science. The validity of the construct found to be cent percent. The test item carries 1 mark for the correct response.

\section{RESULTS AND DISCUSSION}

\section{Analysis}

Comparison between mean scores of Academic Achievement which consists of Hindi, English, Mathematics, Science and Social Science of the three diverse types of schools shows that the first place goes to NGO based school, the second one is Government School and the third one is Private School. The results show that in Hindi achievement test private school students performed well in comparison with the other two. The mean found to be 19.48, in English again the mean found to be 17.10 of private school students, in Mathematics mean found to be 29.82 of the private school, in Science mean found to be 29.88 of the private school, in Social Science mean found to be 47.64 of NGO's based school students. The mean of IQ found to be 29.08 of private school students. Further, the F test was calculated to check the substantial disparities between the academic achievement scores. From Tabel No. $1 \mathrm{~F}$ values for Hindi, English, Mathematics, Science, Social Science and IQ were $40.79,67.80,208.42,367.25,2.50$, and 32.76 respectively and significant at .01 level. It shows that there was the effect of type of school on the academic achievement records of the students. Graph 1.1 indicates that there was a variation among the mean scores of Hindi academic achievements of three different types of school. And among them, the scores of private schools were substantially higher in comparison to the other two. Graph 1.2 indicates that there was a variation amongst the mean scores of English academic achievements of three different types of school.

And among them, the scores of private schools were considerably higher in comparison to the other two. Graph 1.3 indicates that there was a variation amongst the mean scores of Mathematics academic achievement of three different types of school. And among them, the scores of private schools were appreciably higher in comparison to the other two. Graph 1.4 indicates that there was a 
distinction between the mean scores of Science academic achievement of three different types of school. And among them, the scores of private schools were substantially higher in comparison to the other two. Graph 1.5 indicates that there was a variation between the mean scores of Social Science academic achievement of three different types of school.

And among them, the scores of NGO schools were significantly higher in comparison to the other two. Graph 1.6 indicates that there was a variation among the mean scores of the Intelligence Quotient of three different types of school. And among them, the scores of private schools were substantially higher in comparison to the other two.

The present investigation also aimed to study the association concerning academic achievement scores and Intelligent Quotient among primary school children. For the statistical analysis of the obtained raw scores, the product-moment coefficients of correlation were computed to test the hypothesis. A correlation matrix was formed which shows inter-correlation among the proposed variable.

The matrix of the coefficient of correlation (Table- 2) indicates that academic achievement scores are positively correlated with the Intelligence Quotient. Thus, the increase in Intelligence Quotient tends to increase academic achievement. Here are numerous aspects responsible for the differences in the academic achievement Gyanani (1998) studied the consequence of classroom climate, teacher's leadership, behavior and potential of student-teachers academic achievement and found that classroom climate, teacher's leadership, and expectations significantly influenced the scholastic attainment of students.

Agarwal and Kapoor (1998) conducted a study on parent's participation in children's academic activities about their academic achievement at the primary level and found that at the primary level, parents giving direction and guidance at an appropriate time contribute towards children's performance in school. Haseen (1999) examined the scholastic attainment as a meaning of societal class, parentchild communication and dependence behavior and school administration and realized that societal class, parent-child interaction and dependency behavior had a substantial impact on academic achievement.

A longitudinal study by Osborn and Milbank (1987) on more than 8400 children born in the UK during 1970 showed a clear association between pre-school attendance and educational outcomes (reading, mathematics) and social ones (behavior problems) at the age of 10. The researcher argued that pre-school attendance brought about the better cognitive performance seen in children who had attended pre-school "education" but not those who attended "care". After adjusting for the family upbringing and individual differences that might affect their development. Howes (1988) found that kids registered in the higher quality centers had better educational and social outcomes at school. The children from low-quality centers did particularly poorly when they had been enrolled in daycare before their first birthdays. These "early entry" children were distractible, at a low level in task training and had considerable difficulty getting on with peers. Scholastic attainment varies considerably amongst schools regardless of the individual and social characteristics of pupils entering them. School characteristics influence their pupils' attitudes to school, as measured in attendance and their feelings about classes and subjects. Effective schools influence rates of attendance. 


\section{Discussion}

The major finding of this research was that the school makes a larger contribution to the explanation of progress than is made by the pupils' sex, age or social background. The performance of the private school pupils was outstanding, they have shown good results in terms of academic achievement as well as intelligence quotient followed by the schools run by NGO, they also do well in comparison to the government schools.

There were many differences in these three types of schools, they were different in terms of infrastructure, teacher's knowledge, efficiency, and discipline, students' attitude towards the school, towards education and attendance. The students of government schools were less inclined towards attending the school but are more inclined towards the mid-day meal.

They do not want to study, not ready to read, write and learn. Their interest is more about their household-chores, fieldwork and other responsibilities towards their family, but not towards education. For the family is first and education is at the last stage. The observation also shows that teachers of primary basic school also develop a negative attitude about their students, their well-being and upliftment. They are also least bothered about the status of the students. They focus on their self and self-improvement. The picture has a reverse side in the case of NGO's run based school. In these schools, the teachers are more inclined towards the betterment of the students. They do a lot of efforts in making education in a more playful way rather than the monotonous one. The number of cultural activities held in school is also very much. So, students engage in extracurricular activities increase their social belongingness, bonding between them and team-spirit which is less at their homes.

To improve the condition of government schools, the researchers suggested the Government -NGO-Community partnership model (Refer Figure 5) for education. Under this model, most of the funding to run the school will be provided by the government which includes meeting expenses of teachers' salaries, mid-day meals, maintenance of school infrastructure and facilities. The major role of NGOs would be management and administration of the school ensuring hiring of competent and motivated teachers, providing a conducive learning environment, maintenance of school records, conducting extra-curricular activities for the development of student and teachers training programs and establishing rapport with the community to motivate their parents to send their children to school and mobilize students to come to school by sensitizing them about the need of education. NGOs can also garner monetary and physical resources at the local level for providing additional schooling needs to the children which the children belonging to socioeconomically backward cannot afford. In the first phase, this model should be implemented in already established government schools and government funds should be spent on improving the existing infrastructure and facilities of these existing schools instead of opening new schools. This way the model will be low cost and more sustainable. Such models have been successful in South African countries. The efficiency of NGOs in employing more efficient is staff while attempting to maintain a standard of performance equivalent to private schools, the experience of NGOs to design low costs programs, innovative skills, highly motivated manpower to help the society, knowledge at the local level will 
contribute in making the model effective at the local level. Moreover, partnership with the local community makes it easy for NGOs to organize awareness and welfare programs related to education which in turn catalyze student mobilization and parents' participation in children's' education.

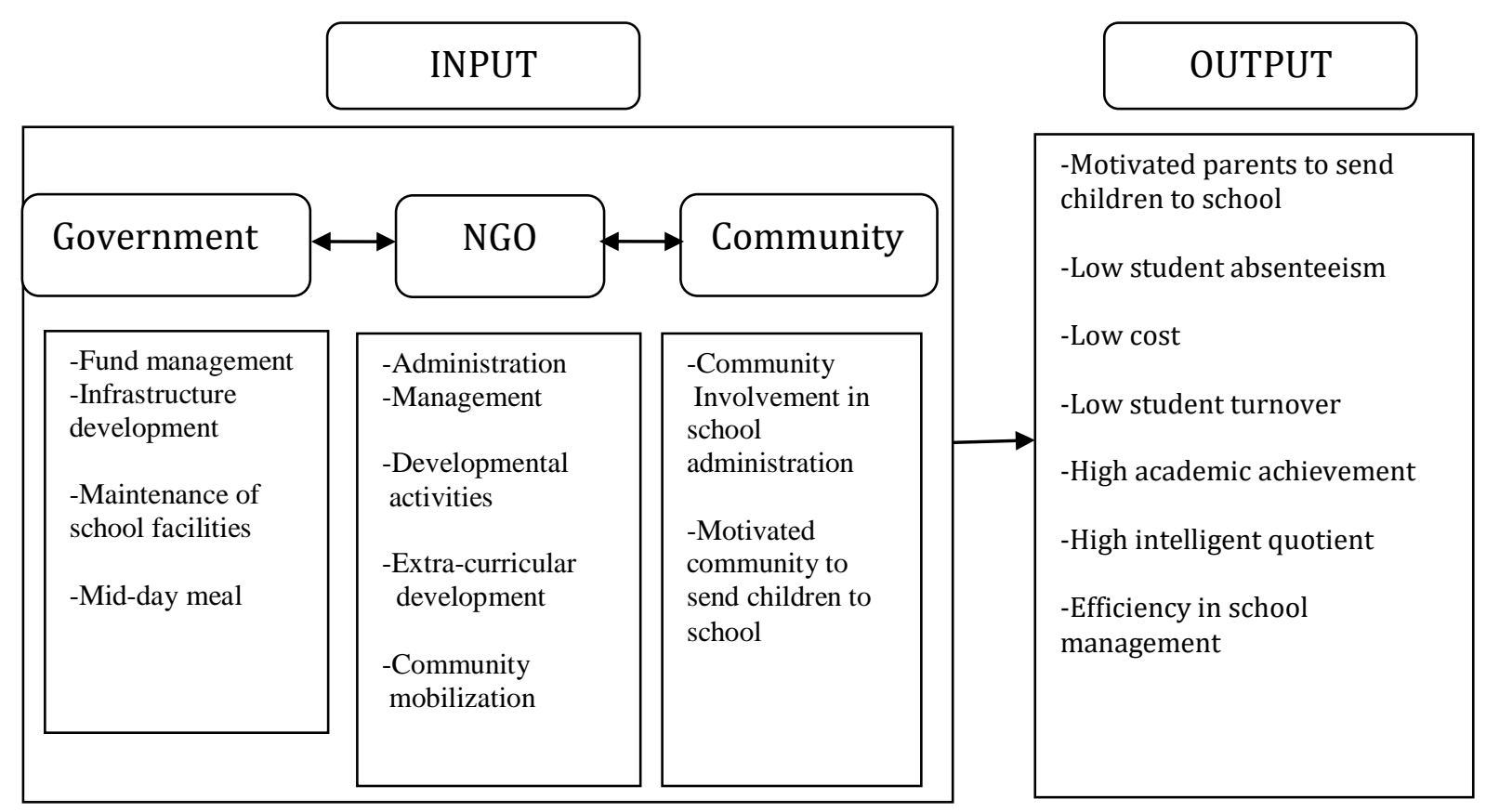

Figure 5: NGO-Government-Community Partnership Mode

Source: Researcher's Construct

\section{CONCLUSION}

The present research concludes that the scholastic attainment of private school children was good as compared to NGOs ' based and government schools. Many factors affect the scholastic out-turn these are socio-economic factors, psychosocial, school and home atmosphere, and student factors. In many studies, a strong and direct correlation was seen between the condition of a school or classroom and student achievement.

In general, student's attendance in school with newer facilities scored more points than those attending in the sub-standard building. Clean drinking water, good light, comfortable school environment, and less classroom noise also have a constructive impact on children's achievement and these findings were consistent with our study. School and outside of school dynamics equally require to be upgraded for attaining the standard of primary school.

The good teacher serving as a guide, instructor, and consultant and using appropriate materials and methods of instructions contribute to creating a 
favorable learning environment for the children which is not present in teachers of government schools. To attain high achievement of NGO based and governmentbased schools, the researchers suggested a sustainable Government-NGOCommunity partnership model. The model will bring in more efficiency in school management resulting in low student turnover, low absenteeism, high academic achievement, high intelligent quotient, etc. The sustainability of the partnership model can be studied in future research.

\section{IMPLICATION \& RECOMMENDATION}

Student's academic achievement is strongly determined by the quality of the school in which they study. Students who adore their school do improve academically. An important implication for educational practices may derive from these findings since they can provide valuable information to design instructional actions programs that can improve student accomplishment and fulfillment are two of the utmost vital education products and reflected crucial pointers of teaching quality

This research suggested that policies must emphasize a balance between concerns with high achievement and concerns with the meeting in individuals learning and motivational, emotional, and social needs of diverse students. It should value outcomes that go beyond academic achievement to emotional and social outcomes that include increased personal and social responsibility and caring. It is also recommended that safe, caring, and orderly environments are conducive to learning, socially engaging strategies, such as a cooperative learning environment, contribute to academic achievement.

\section{REFERENCES}

Agarwal ,Y.P. and Kapoor, N., (1998) Parental participation in children's academic activities in relation to their academic achievement. Journal of Indian Education, Vol. 23 (4), pp. 61-68.

Agarwal, Y. P. \& Chugh, S. (2003). Learning Achievement of Slum Children in Delhi. National Institute of Educational Planning and Administration: New Delhi.

Anandharaja, S., Balakrishna, V., \& Lawrence, A.J. (2016). Development and Standardization of Academic Achievement Test in Social Science. International Journal of Research and Development, 1(1), 2456-3137.

Batley, R. \& Rose, P. (2010). Achieving Education for All through Public-Private Partnerships. Taylor and Francis, 20, 4(5).

Bong, M. \& Clark, R.E. (1999). Comparison between self-concept and self-efficacy in academic motivation research. Educational Psychologist, 34, 139-153.

Bong, M., \& Skaalvik, E.M. (2003). Academic self-concept and self-efficacy: How different are they really? Educational Psychology Review, 15, 1-40.

Cattell, R.B., \& Butcher, H. j. (1968). The prediction of achievement and creativity. 
Fischer, C. S., Hout, M., Jankowski, M. S., Lucas, S. R., Swidler, A., \& Voss, K. (1996). Inequality by design: Cracking the bell curve myth. Princeton, NJ: Princeton University Press.

Good, T., \& Brophy, J. (1986). School effects. In. M. Wittrock (Ed.). Handbook of research on teaching (3rd ed.) (pp. 570-602). New York: Macmillan.

Gottfredson, L. S. (1998, Winter). The general intelligence factors. Scientific American Presents, 9(4), 24-29.

Gouda J., Das, K.C. Goli, S., \& Pou, L.M. A. (2013) "Government versus private primary schools in India: An assessment of physical infrastructure, schooling costs and performance". International Journal of Sociology and Social Policy, Vol. 33 Issue: 11/12, pp.708-724

Gyanani. T.C. 1998. Effect of classroom climate, Teacher's leadership behaviour and expectations on students Teacher's scholastic achievement. Indian Educational Review, 34(2).

Habibullah, S. \& Ashraf, J. (2013). Factors Affecting Academic Performance of Primary School Children. Pakistan Journal of Medical Research, 52 (2), 4752.

Haseen, T. (1999) Academic achievement as a function of social class. Parent child interaction dependency behaviour and social Management. Psycholinguan 29, 153-158.

Helms-Lorenz, M., \& Van de Vijver, F. J. R. (1995). Cognitive assessment in education in a multicultural society. European Journal of Psychological Assessment, 11(3), 158-169.

Herrnstein, R. J., \& Murray, C. (1994). The bell curve: Intelligence and class structure in American life. New York, NY: Free Press

Howes, C. (1988). Relations between early childcare and schooling. Developmental Psychology, 24(1), 53-57.

Imam, A., Singh, G.P., \& Tiwari, Y.N. (2016). Comparative study of schools under government and private management with respect to achievement at secondary stage of education in the District of Lucknow. International Journal of Advanced Education and Research, 1(10), 25-29

Jensen, A. R. (1998). The g factor: The science of mental ability. Westport, CT: Praeger

Kaya, F., Juntune, J., Stough, L. (2015). Intelligence and Its Relationship to Achievement. Elementary Education Online, 14 (3), 1060-1078.

Koretz, D. (1997). Indicators of educational achievement. In R. M. Hauser, B. V. Brown, \& W. R. Prosser (Eds.), Indicators of children's well-being (pp. 208234). New York, NY: Russell Sage Foundation

Lindquits, E. F. (1957). The Iowa Test of Educational Development: Confidential Summary report of Average Scores. Chicago, IL: Science Research Associates. 
Matrices and Vocabulary Scales - Section 2: Coloured Progressive Matrices.

Merton, R. K. (1973). The Matthew effect in science. In N. W. Storer (Ed.), The sociology of science: Theoretical and empirical investigations (pp. 439459). Chicago: University of Chicago Press.

National Educational Policy; National Informatics Centre

Osborn, A. F. \& Milbank, J. E. (1987). The Effects of Early Education. Oxford University Press.

Paul Glewwe \& Ana Cuesta \& Booke Krause, 2016. "School Infrastructure and Educational Outcomes: A Literature Review, with Special Reference to Latin America,"Economía Journal, The Latin American and Caribbean Economic Association - LACEA, vol. 0(Fall 2016), 95-130.

Raven, J.C., Court, J.H. \& Raven, J.C. (1990). Manual for Raven's Progressive. Oxford Psychologist Press: San Antanio. England.

Sandal, O., \& Dur, W. (2000). The school environment and the health of adolescents. In C. Currie, K. Hurrelmann, W. Settertobutle, R. Smith, \& J. Todd (Eds.), Health and health behavior among young people: A WHO cross-national study (HBSC) international report (pp.49-64). WHO policy series: Healthy Policy for Cildren and Adolescents. Series No.1.

Singh, R.B. (2008). The Achievement Test Battery ATB-SR. National Psychological Corporation: Agra. India.

Singh, T.S. (2014). A Comparative Study on the Academic Achievements between the Students of Private and Government High Schools within Imphal East district (Manipur). Voice of Research. 3(1)

Sternberg, R. J. (2003). Wisdom, intelligence, and creativity synthesized. New York, NY: Cambridge

Sylva, K. (1994). School influences on Children's Development. Journal of Child Psychology and Psychiatry, 35(1), 135-170.

Theobold, M.A. (2005). Increasing student motivation. Thousand Oaks, CA: Sage.

Watkins, M. W., Lei, P.-W., \& Canivez, G. L. (2007). Psychometric intelligence and achievement: A cross-lagged panel analysis. Intelligence, 35(1), 59-68. 